\title{
A participação da sociedade civil brasileira na educação de jovens e adultos e na CONFINTEA VI
}

\author{
Sérgio Haddad
}

Ação Educativa, São Paulo

\section{Antecedentes}

O envolvimento da sociedade civil no campo da educação de adultos no Brasil não é novo na nossa história. Sempre houve um forte papel da Igreja católica nesse campo, desde o período colonial, assim como a participação dos sindicatos no período republicano. Não podemos esquecer também do envolvimento dos movimentos sociais, em especial dos de cultura popular, na primeira metade dos anos de 1960, assim como do trabalho das escolas comunitárias nas periferias dos grandes centros urbanos, em especial nas regiões Norte e Nordeste. ${ }^{1}$

Nas décadas de 1960 e 1970, um conjunto de pequenas organizações - associações civis sem fins lucrativos, as organizações não-governamentais -, em parceria com as pastorais sociais da Igreja católica, organizou-se para dedicar-se ao trabalho de educação popular com os setores mais pobres da população.

\footnotetext{
${ }^{1}$ Sobre a temática, ver As organizações da sociedade civil $e$ as organizações não-governamentais de educação (Haddad \& Oliveira, 2001).
}

O que se buscava com esses processos educativos, principalmente com adultos, era ampliar o nível de compreensão que a população pobre tinha das suas condições de vida, discutindo suas causas e desenhando estratégias para uma atuação crítica na sociedade, sob forte influência do pensamento de Paulo Freire. Eram totalmente desligados dos sistemas públicos de ensino, que estavam controlados pela ditadura.

Ao mesmo tempo, entre as orientações das teorias educacionais críticas vigentes naquele momento histórico estava a teoria crítico-reprodutivista, que compreendia os trabalhos junto aos sistemas de ensino como de caráter disseminador das ideologias dominantes e muito mais afeita a reproduzir as relações de classe existentes do que a produzir uma nova ordem social. ${ }^{2}$ Muitos abriram mão de trabalhar com o Movimento Brasileiro de Alfabetização (MOBRAL) e com o ensino supletivo, ações escolares públicas do período voltadas à educação de adultos, por optar politicamente por um trabalho não-institucionalizado e de caráter não-escolar.

${ }^{2}$ Sobre o tema das teorias crítico-reprodutivistas, ver Saviani (2008). 
Em linhas gerais, as orientações pedagógicas dessas experiências expressavam-se na ideia de que os grupos populares detinham um saber particular, produzido a partir das suas práticas sociais e de suas condições de vida, e de que os processos educativos ocorriam a partir do encontro entre esses saberes e os saberes dos educadores. Portanto, a missão educativa desses educadores não se realizava descolada de uma intencionalidade política.

\section{O período de democratização da sociedade brasileira}

No final da década de 1970 e início dos anos de 1980, dois fatores marcaram o trabalho educativo desenvolvido pela sociedade civil no campo da educação de jovens e adultos (EJA). Um deles foi o crescimento da diversidade de práticas educativas para além das pastorais da Igreja católica. Eram os movimentos de bairros, as associações de moradores e organizações populares, os movimentos sindicais que se constituíam à margem do movimento sindical oficial, os movimentos de mulheres e o movimento negro, os movimentos autônomos de luta por moradia, terra e trabalho.

Com isso, as experiências de educação popular, nesse segundo momento, não se ativeram apenas às questões materiais de produção e reprodução da vida; voltaram-se também para os temas relativos ao plano cultural e simbólico, como as relações de gênero, etnia e raça. A sociedade civil contribuiu para demarcar, no processo de redemocratização da sociedade brasileira, os temas da desigualdade e da diversidade para além da democracia formal de respeito aos direitos individuais e políticos. O conceito restrito de direitos humanos ampliou-se para uma concepção contemporânea, incluindo os direitos econômicos, sociais, culturais e ambientais.

Outro fator que envolveu o trabalho da sociedade civil foi a luta pela construção de um ensino público de qualidade, inclusive para os jovens e adultos. Com a democratização da sociedade, o próprio movimento social colocou entre suas demandas a questão da escola pública como prioridade no campo do empoderamento dos grupos populares. Tratava-se agora de contemplá- la como um direito social, no âmbito dos direitos humanos e de cidadania; como de responsabilidade do poder público, portanto.

Com a democratização das estruturas do poder, a constituição de novos partidos e a vitória da oposição em muitas prefeituras, atores sociais que antes atuavam no campo da educação popular foram trabalhar em governos. Nesse lugar social, passaram a repensar uma nova proposta de escola baseada na demanda popular e voltada aos interesses das maiorias.

Definiu-se uma nova configuração da relação entre a sociedade e o poder público. Entidades da sociedade civil passaram a pautar e desenvolver ações de assessoria aos setores públicos, bem como a atuar na luta pelo acesso e pela qualificação dos serviços públicos de ensino voltados aos interesses populares. Se, em alguns momentos, a constituição de uma escola popular, gerida pela sociedade, paralela aos sistemas públicos do ensino, foi pauta dos movimentos sociais e das organizações não-governamentais, é verdade que, dada a necessária institucionalização que os processos escolares exigem, tais escolas populares se mostraram inviáveis de serem mantidas no longo prazo sem apoio do poder público. Passou-se ao tema do controle social sobre as instâncias públicas de ensino. Passou-se a cobrar a participação das comunidades escolares e a criar mecanismos internos de democratização da escola pública.

O período compreendido pela eleição de um presidente civil em 1985, ainda que de forma indireta, a Constituição Federal de 1988 e a elaboração da nova Lei de Diretrizes e Bases da Educação Nacional (LDB), em 1996, foi marcado pela forte participação de sociedade civil no campo da EJA. No campo acadêmico, educadores e pesquisadores da EJA passaram a constituir um conjunto de pesquisas e atividades que resultaram nas informações necessárias para subsidiar as novas e antigas experiências nos sistemas públicos de educação de jovens e adultos, ampliando o leque de atores sociais preocupados com a temática. ${ }^{3}$

${ }^{3}$ Ver o conjunto de trabalhos realizados como estados-daarte (Haddad, 1987, 2002), bem como a constituição do grupo de estudo e posteriormente Grupo de Trabalho em Educação de Jovens 
Em 1985, antes do período constituinte com o Governo Sarney, o MOBRAL, principal programa de alfabetização dos governos militares, foi transformado na Fundação Educar, descentralizando sua atuação e apoiando projetos da sociedade civil; já configurava nesse fato a tendência de descentralização e participação social que se verificaria posteriormente em decorrência da nova Constituição.

Na linha dos conselhos de políticas, a sociedade civil voltou a ser chamada para participar da Comissão Nacional de Alfabetização, composta com representação de diversos setores da sociedade civil e do poder público, como o Conselho de Secretários Estaduais de Educação (CONSED), União dos Dirigentes Municipais de Educação (UNDIME), Associação Brasileira de Organizações Não-Governamentais (ABONG), Conselho dos Reitores das Universidades Brasileiras (CRUB), Sistema S (Serviço Social da Indústria SESI, Serviço Nacional de Aprendizagem Industrial SENAI, Serviço Social do Comércio - SESC, Serviço Nacional de Aprendizagem Comercial - SENAC), sindicatos e movimentos sociais.

Novas redes de educadores de adultos foram conformadas. Destacam-se entre elas o Conselho de Educação de Adultos da América Latina (CEAAL), fundado em 1982, que mantém no Brasil um conjunto de filiados, e a Rede de Apoio à Ação Alfabetizadora do Brasil (RAAAB), articulação de entidades e pessoas do campo.

\section{O Governo Fernando Henrique Cardoso}

Durante o Governo Fernando Henrique Cardoso (1995-2002), o Brasil viveu intensa crise econômica, acompanhada de políticas neoliberais que produziram uma reforma do Estado, com privatização de bens públicos e forte pressão para desregular direitos recém-constituídos.

No campo da educação, a política do governo federal restringiu-se a concentrar seus esforços na expansão

e Adultos da Associação Nacional de Pesquisa e Pós-Graduação (ANPEd) (www.anped.org.br). do ensino fundamental. Assim, os direitos à escolarização de jovens e adultos, conquistados na elaboração da Constituição Federal de 1988, não receberam adequada amplitude na LDB de 1996, o que se verificou também na exclusão da modalidade EJA do Fundo de Manutenção e Desenvolvimento do Ensino Fundamental e de Valorização do Magistério (FUNDEF), principal fonte de financiamento da educação no período.

Outro aspecto importante foi a redefinição dos limites entre o público e o privado. Na orientação neoliberal, a sociedade civil foi chamada para colaborar diretamente com a oferta dos serviços educacionais, dentro da lógica de diminuição das responsabilidades do Estado. Ganharam relevância entidades de prestação de serviços, entidades filantrópicas ou de caráter assistencial e verificou-se crescente interesse de parte dos grupos empresariais e do capital em geral nos rumos e no controle das orientações e no atendimento educacional. Com o enfraquecimento do setor público em função da diminuição do corpo técnico das diversas secretarias, pessoas e entidades privadas foram chamadas a produzir materiais didáticos, treinar professores e atuar no plano das orientações pedagógicas.

As formas de participação, no entanto, variam de acordo com a conformação dos governos nas diferentes esferas. As administrações municipais do Partido dos Trabalhadores (PT) desenvolveram experiências participativas, grande parte com o modelo Movimento de Alfabetização (MOVA), criado inicialmente na cidade de São Paulo, quando Paulo Freire estava no comando da Secretaria Municipal da Educação. Convocados para uma grande ação alfabetizadora, movimentos e entidades sociais foram chamados a cogestionar um programa municipal, no qual grande parte da governança ficava nas mãos dessas organizações. O MOVA ganhou notoriedade nacional e passou a ser implantado em diversas prefeituras, criando inclusive uma articulação nacional de educadores e educandos que permanece até hoje como rede e com encontros nacionais regulares.

Os desafios produzidos naquela conjuntura podem ser identificados no trecho a seguir, retirado de documento produzido por organizações não- 
governamentais de educação de Minas Gerais em 1994, quando do encontro realizado para discutir as atividades relativas ao Programa Educação para Todos:

Se no momento histórico de seu nascimento e fortalecimento boa parte das ONGs tiveram que reforçar seu caráter alternativo ao Estado e a outras iniciativas ditas “assistencialistas”, hoje é preciso com lucidez dizer que isso não basta. Isto não basta por que as ONGs, por sua ligação com a população, por sua capacidade de articular-se politicamente, pela experiência acumulada, não podem se furtar ao dever de propor alternativas viáveis para o conjunto da população.

É preciso fortalecer o campo das experiências que ocorrem fora do aparelho estatal, mas só que agora não apenas para servir-lhe como alternativa, mas também como parâmetro. [...] é preciso, a muitas ONGs de diversas naturezas, compreender que na verdade elas já participam e são parte da política pública. Isto por dois motivos: em primeiro lugar porque nos últimos anos temos construído na América Latina um sentido do público que ultrapassa o estatal, inclusive para questionar um Estado que tem sido muito pouco público. Por outro lado, boa parte das ONGs se mantém com algum tipo de recurso público, seja este estatal ou não.

Assumir esse seu caráter público traz para as ONGs [...] propor e discutir a partir de dentro das políticas públicas e não apenas como alguém de fora do aparelho estatal. Isto seria condição, também, para que as ONGs não sirvam apenas de “correia de transmissão" ou executores de políticas definidas por técnicos e burocratas, mesmo que bem intencionados.

Afirmar o caráter público das ONGs e sua legitimidade em propor e viabilizar políticas públicas implica hoje numa capacidade de formular uma crítica fundamentada na ideia de privatização dos serviços estatais. Não podemos legitimar as ideias de que os Estados na América Latina devem privatizar como meio de resolver os graves problemas econômicos e sociais [...]. Pensar a qualidade da educação escolar para as ONGs deve significar pensar numa experiência que, incorporando a aprendizagem de conhecimentos, seja muito mais que isto: seja elemento formador e potencializador das várias dimensões do ser humano. Só conseguiremos realizar essa tarefa se tirarmos a discussão da qualidade em educação do campo da lógica do mercado e da produção. É preciso discutir eficiência, produtividade e outras categorias, não na forma como foram elaboradas para dar conta de processos produtivos, a lógica do mercado, mas na lógica das relações sociais e culturais, que se dão, em última instância, nas relações pedagógicas no interior da escola. (Faria Filho, 1994, p. 17)

\section{A V CONFINTEA e a participação da sociedade civil}

A Conferência Internacional de Educação de Adultos (CONFINTEA), promovida pela Organização das Nações Unidas para a Educação, a Ciência e a Cultura (UNESCO) e realizada a cada doze anos, é o único evento global de educação de adultos. A primeira foi realizada na Dinamarca (1949), e as demais no Canadá (1960), no Japão (1972), na França (1985) e, por último, na Alemanha (1997).

A V CONFINTEA, realizada em Hamburgo em julho de 1997, desenvolveu suas atividades ainda sob o impacto da morte do educador brasileiro Paulo Freire, ocorrida em dois de maio, e em meio às reformas produzidas pelo Governo Fernando Henrique Cardoso.

Hamburgo vivenciou momentos de homenagem ao educador e cidadão do mundo. Um vídeo projetado no enorme salão da conferência mostrou Paulo Freire em uma fala sobre seus temas recorrentes; chamava a atenção para as injustiças do mundo e para o compromisso de educadores em construir sociedades nas quais prevalecesse democracia com justiça social. A justa homenagem prestada pelos quase dois mil participantes de mais de 150 países do mundo contrastava com a profunda injustiça ocorrida no encontro regional da América Latina e Caribe, preparatório à V CONFINTEA, realizada no Brasil em janeiro de 1997, quando a presença de Paulo Freire foi impedida por razões de natureza político-partidária, mostrando o quanto seus ideais ainda estavam distantes de se realizar, a começar em seu próprio país.

Mas seria uma injustiça identificar a "presença" de Paulo Freire apenas nos aspectos formais da reunião. Na verdade, sua verdadeira presença pôde ser reconhecida nas inúmeras influências do seu pensamento nos debates, nas referências e nas análises que 
permearam os processos preparatórios da conferência e a sua realização. ${ }^{4}$

O movimento de educação de adultos viu na $\mathrm{V}$ CONFINTEA uma oportunidade para tornar visível o tema da educação de jovens e adultos no contexto brasileiro e para tomar seus documentos e acordos firmados como instrumentos de luta para a garantia do direito constitucional.

Para construir o documento nacional, o processo foi coordenado pela Comissão Nacional de Educação de Jovens e Adultos (CNEJA), que orientou os estados para que fizessem seus encontros e seminários preparatórios com a participação da sociedade civil. Nem todos produziram seus documentos dessa forma, mas o movimento de educação de adultos procurou participar onde foi demandado e onde conseguiu influir. De qualquer forma, o sentido participativo e de consulta estava dado no processo brasileiro pela primeira vez ao longo da história das diversas CONFINTEAs. Estávamos em pleno ciclo de conferências das Nações Unidas, nas quais a sociedade civil mundial passou a participar como forma de pressão sobre os governos para que os direitos de cidadania fossem contemplados nos acordos firmados.

O encontro nacional, realizado na cidade de Natal, foi o momento-síntese do processo preparatório brasileiro, com representantes de órgãos públicos e setores da sociedade civil dos diversos estados brasileiros. Alguns fatos desencadeados nesse processo e nos momentos seguintes ao encontro de Natal demonstram as contradições desse novo momento, quando a sociedade civil estava sendo chamada a intervir no processo de construção das políticas públicas.

Em Natal, o governo brasileiro lançou oficialmente o Programa Alfabetização Solidária (PAS), para surpresa dos presentes e sem consulta prévia à CNEJA, tendo como orientação o formato de campanha, bastante criticado inclusive no próprio documento brasileiro. O PAS foi alocado sob a responsabilidade da Comunidade Solidária, que tinha a primeira-dama como coordenadora. Houve nesse momento uma clara

${ }^{4}$ Sobre essa temática, ver Haddad (1998). opção por levar a responsabilidade pela superação do analfabetismo de jovens e adultos para o campo das políticas compensatórias, deslocando a sua centralidade do Ministério da Educação para a ação das políticas tradicionais de alívio de pobreza, de natureza compensatória, tradicional no trabalho realizado pelas primeiras-damas.

O encontro também produziu uma série de tensões entre o poder público e a sociedade civil no que diz respeito ao conteúdo do documento final. O governo brasileiro, no entanto, apresentou uma versão diferente em Hamburgo, criando constrangimento aos representantes da sociedade civil presentes. ${ }^{5}$ Após o encontro, a coordenadora nacional de EJA, nitidamente favorável à aliança com a sociedade civil para a garantia dos direitos educativos dos jovens e adultos, foi afastada e a Comissão Nacional não mais convocada, em uma evidente atitude de isolar a pressão que a sociedade civil fazia, claramente insatisfeita com a orientação das políticas na área.

Apesar desses acontecimentos, o evento acabou por constituir importantes articulações, que influíram de maneira significativa no modo de participar da sociedade civil nos anos seguintes; em especial, a mobilização impulsionou o surgimento dos Fóruns de Educação de Jovens e Adultos. O primeiro surgiu em 1996, no Rio de Janeiro, e gradativamente foram se organizando em todos os estados brasileiros.

Os fóruns estaduais propiciaram a constituição de fóruns regionais, articulações que levaram à desconcentração dos fóruns nas capitais. Os fóruns estaduais e regionais acabaram por levar à organização dos Encontros Nacionais de Educação de Jovens e Adultos (ENEJAs). O primeiro foi realizado no Rio de Janeiro em 1999; em seguida, realizaram-se anualmente, cada vez em um estado. ${ }^{6}$ Os fóruns são espaços de encontro de diversos atores sociais, educadores, ativistas, pesquisadores e gestores públicos e privados de programas de educação de jovens e

As duas versões encontram-se no volume 1 da coleção Educação para Todos, 2004, MEC e UNESCO.

${ }^{6}$ Sobre o tema, ver Soares (2004) e Paiva (2007). 
adultos. Têm como característica a horizontalidade, abertos aos que se dispõem a participar, sem restrições de natureza ideológica. Trata-se de um espaço de troca de experiências e informações, bem como de articulação para participação nos demais encontros, sem se constituir em uma estrutura verticalizada e de direção centralizada. Os fóruns escolhem suas lideranças e coordenadores de maneira autônoma.

Nos anos seguintes, os fóruns ganharam relevância, passando a ser o grande espaço de articulação e participação do movimento de educação de jovens e adultos. Por sua natureza horizontal e pela participação crescente de uma diversidade de atores, públicos e privados, suas características passam a ser de articulação para a formação, troca de informações e atualização sobre o campo da educação de jovens e adultos, perdendo parte da sua natureza de conflitividade e controle sobre o poder público.

\section{Governo Lula}

Neste início do século XXI, as ações no campo da EJA foram marcadas pela nova conjuntura do Governo Lula. Após o esgarçamento das políticas neoliberais do governo anterior, com poucos avanços nos planos econômico e social, o novo presidente da República assumiu seu governo prometendo emprego (10 milhões de novos empregos), alfabetização (superar o analfabetismo de jovens e adultos) e comida (fome zero: três refeições por dia para todos). Uma bandeira tipicamente social, mostrando que a prioridade do seu governo seria de natureza diferente dos governos anteriores, cuja estabilidade econômica era o foco principal, em função das políticas de ajuste e orientações dos organismos internacionais.

O início da nova gestão mostrou conservadorismo no plano econômico, tentando acalmar o grande capital e o setor financeiro e, para isso, basicamente mantendo as mesmas políticas do governo passado. Em contrapartida, ao contrário do governo anterior, fortaleceu a política de transferência de renda para os mais pobres, cumprindo a promessa de campanha de permitir acesso ao consumo de alimentos à vasta popu- lação empobrecida. No plano do emprego, suas metas ficaram bastante distantes do prometido naquele início de governo e a superação do analfabetismo esbarrou em políticas tradicionais e pouco eficientes, apesar do reconhecimento do direito e do retorno das políticas de EJA para a condução do Ministério da Educação.

O segundo mandato, diferentemente do primeiro, vem colocando ênfase no discurso sobre o crescimento econômico, centrado no Programa de Aceleração do Crescimento (PAC). No entanto, não foram poucos os resultados na área social, o que vem colocando o presidente Lula entre os presidentes mais populares da história brasileira, ao menos até a metade de 2009, quando este texto está sendo elaborado.

Não cabe aqui uma análise ampla desse governo, das suas dinâmicas políticas e dos resultados de seus dois mandatos, mas cabe destacar os temas que dizem respeito às políticas de EJA, o efeito VI CONFINTEA para o Brasil e o papel da sociedade civil nesse contexto.

Tradicionalmente, no Brasil o governo federal tem assumido, não de maneira exclusiva, a responsabilidade por campanhas e programas de alfabetização de adultos, relegando aos estados e municípios a continuidade dos estudos no ensino fundamental e no ensino médio.

Desde a extinção do MOBRAL, em 1985, o governo federal vem financiando e dando apoio técnico aos estados, municípios e entidades da sociedade civil, deixando de exercer papel direto na implementação de programas de alfabetização de adultos. Isso começou com a transformação do MOBRAL em Fundação Educar, e teve continuidade no PAS e no atual Brasil Alfabetizado, do Governo Lula. Mais recentemente, o Brasil Alfabetizado vem gradativamente deixando de financiar entidades da sociedade civil para apoiar apenas governos em sua missão alfabetizadora.

Tem havido um claro processo de municipalização da EJA nas primeiras etapas do ensino fundamental, conforme orienta a Constituição Federal e aLDB, ficando os demais níveis de ensino sob responsabilidade do governo estadual. No primeiro segmento do ensino fundamental, os municípios responderam 
por $80 \%$ da matrícula de jovens e adultos em 2006 , ficando os estados com $54 \%$ das matrículas no $2^{\circ} \mathrm{seg}-$ mento do ensino fundamental presencial e por $88,2 \%$ das matrículas no ensino médio (Di Pierro, Vóvio \& Andrade, 2008).

Com o Governo Lula, a União retomou a coordenação de uma política de educação de jovens e adultos, devolvendo ao Ministério da Educação a responsabilidade por essa modalidade de ensino.

Para exercer a função de regulação das políticas, a partir de 2004 o Ministério da Educação (MEC) reuniu a gestão dos programas de apoio à alfabetização e Ensino fundamental de Jovens e Adultos em uma nova Secretaria de Alfabetização, Educação Continuada e Diversidade (SECAD) e instituiu uma Comissão Nacional para consulta aos municípios, estados e organizações da sociedade civil ${ }^{7}$. Essas medidas conferiram maior coerência e eficácia às iniciativas do MEC para essa etapa de ensino, mas não foram suficientes para superar as dificuldades de coordenação interministerial dos programas de educação de jovens e adultos, dispersos em distintos órgãos do governo federal. (Di Pierro, Vóvio \& Andrade, 2008, p. 40-41)

${ }^{7}$ Criada pelo decreto n. 4.834/03 para tratar exclusivamente da alfabetização de jovens e adultos, a Comissão Nacional de Alfabetização e Educação de Jovens e Adultos (CNAEJA) teve seu âmbito e composição ampliados pelo decreto n. 5.475/04 e reafirmados pelo decreto n. 6.093/07. Sua composição recente foi estabelecida pela portaria n. 602, de março de 2006 (http://www. forumeja.org.br/cnaeja/). É formada por 17 membros, sendo quatro representantes dos governos federal (Secretaria de Educação Continuada, Alfabetização e Diversidade - SECAD - e Secretaria de Educação Básica - SEB -, MEC), estaduais (Conselho Nacional de Secretários de Educação) e municipais (União Nacional dos Dirigentes Municipais de Educação); um representante da UNESCO e um das instituições de ensino superior; e dez representantes da sociedade civil (fóruns de EJA, movimentos de alfabetização, trabalhadores da educação, movimentos sociais do campo, de indígenas, afrodescendentes e juvenis, bem como organizações não-governamentais dedicadas a questões da educação e do meio ambiente).
$\mathrm{Na}$ verdade, são vários os programas desenvolvidos pelo governo federal em diversas secretarias do próprio MEC e de outros ministérios que, junto com a diversidade de projetos e programas desenvolvidos por estados, municípios e entidades da sociedade civil, conformam um conjunto bastante amplo, desarticulado e diverso de propostas, de difícil coordenação e com baixo nível de atendimento ante os elevados índices de analfabetismo e a baixa média de escolarização da população brasileira.

Outro fator que condiciona o desempenho das políticas de EJA é o baixo nível de financiamento dessas ações, que acaba por estimular programas de curta duração, com monitores leigos e em parcerias com entidades da sociedade civil. ${ }^{8}$

Ainda do ponto de vista das articulações e do movimento da EJA, os fóruns passaram a ganhar crescente apoio do governo federal. Um portal dos fóruns (www.forumeja.org.br) foi construído, integrando os diversos sites dos fóruns estaduais e produzindo informações de interesse de todos. Por sua vez, os ENEJAs ganharam maior apoio financeiro e crescem em número de participantes.

O movimento EJA no Governo Lula aproximouse do governo federal, acompanhando o movimento já ocorrido em outros municípios e espaços onde governos progressistas assumiram o poder. Nascido das experiências de educação popular nas décadas de 1960 e 1970 como oposição ao regime militar, o movimento de EJA ganhou relevância na luta institucional pelo reconhecimento da escolarização de jovens e adultos como um direito humano fundamental na nova Constituição Federal e na nova LDB. No Go-

\footnotetext{
${ }^{8}$ As parcerias configuram uma estratégia duplamente conve-
} niente ao poder público, pois atende às demandas de participação dos movimentos e organizações sociais ao mesmo tempo em que permite desonerar a máquina pública de encargos permanentes, como a contratação de pessoal docente. Dentre os riscos da difusão da estratégia de parcerias está a desresponsabilização do poder público e a oferta de ensino em condições físicas precárias por educadores que nem sempre possuem formação adequada. Sobre a temática, ver Di Pierro (2005). 
verno Fernando Henrique Cardoso, o movimento foi empurrado para uma postura crítica e de oposição; agora, no Governo Lula, identifica-o como um parceiro e por ele é reconhecido como interlocutor. Conforme o portal dos fóruns:

\begin{abstract}
O crescimento dos fóruns nacionalmente e sua expressão nacional pelos Enejas tornaram o MEC um interlocutor privilegiado, com o qual os fóruns vêm travando parcerias e contribuindo na formulação e efetivação de ações na área. A legitimidade dos fóruns vem sendo reconhecida em muitos espaços, especialmente representados pela ocupação de um lugar na Comissão Nacional de Alfabetização e Educação de Jovens e Adultos - CNAEJA, assim como em um colegiado de representantes com o qual o Ministério tem dialogado permanentemente. ${ }^{9}$
\end{abstract}

\section{A VI CONFINTEA e a participação da sociedade civil}

É dentro desse clima colaborativo que, pela primeira vez na história das CONFINTEAs, ela será realizada no hemisfério sul, na América do Sul, no Brasil, em Belém do Pará. O Brasil ofereceu à UNESCO sua candidatura para realização do evento; uma única outra candidatura concorreu com a brasileira, a da África do Sul, que, ao final, se retirou. Mesmo assim, a definição por parte da UNESCO tardou em ser tomada. Foi preciso ampla mobilização de várias entidades da sociedade civil mundial, capitaneada pelo Conselho Internacional de Educação de Pessoas Adultas (ICAE), que articulou cartas de vários continentes pedindo que o encontro fosse realizado no Brasil. As cartas foram encaminhadas ao então secretário da SECAD, Ricardo Henriques, que as entregou pessoalmente ao diretor-geral da UNESCO, Koichiro Matsuura, em um encontro de ministros da Educação realizado em Buenos Aires. Finalmente, a decisão foi tomada.

Comenta-se que a UNESCO temia por realizar uma reunião como esta na América Latina, com gover-

\footnotetext{
${ }^{9}$ www.forumeja.org.br/historico.
}

nos majoritariamente progressistas, e particularmente no Brasil, com forte tradição em educação popular e forte presença de sociedade civil. Mas, ao final, com o apoio dessa mesma sociedade civil e diante da falta de alternativas, a UNESCO anunciou a VI CONFINTEA no Brasil, designando o Instituto da UNESCO para a Aprendizagem ao Longo da Vida (IUL) como a instância responsável pela organização do evento. Como processo preparatório, foram solicitados relatórios nacionais aos Estados-membros; posteriormente, encontros regionais produziram relatórios-síntese de cada região; finalmente, foi encomendada a elaboração do documento denominado Relatório Global sobre a Educação de Adultos (GRALE), elaborado por uma equipe de especialistas contratados a partir dos relatórios-síntese regionais e de pesquisas internacionais, a ser apresentado durante a reunião no Brasil. A IUL organizou ainda um grupo consultivo para apoiar o processo de organização da CONFINTEA, com a representação de setores governamentais, organismos multilaterais, acadêmicos e ativistas.

Os relatórios nacionais entregues pelos paísesmembros chegaram a 151. Foi especialmente alta a taxa de participação na África subsaariana (42 de um total de 47 países entregaram relatórios) e nos países árabes (18 de um total de 22). Em nenhuma região a taxa de retorno foi menor do que 70\% (UNESCO, 2009). Foram produzidos de forma bastante desigual, alguns por equipes governamentais, outros por contratação de empresas de consultoria ou organizações não-governamentais, outros ainda por meio de processos participativos com a presença dos setores público e privado e de organizações da sociedade civil. O Brasil destacou-se por sua forma ampla e participativa de construir o documento nacional, como será comentado adiante.

Entre setembro de 2008 e janeiro de 2009, realizaram-se os cinco encontros regionais preparatórios, um em cada continente, com o objetivo de obter perspectivas regionais sobre a aprendizagem e a educação de adultos: América Latina: de 10 a 13 de setembro de 2008, na Cidade do México (México); Ásia e Pacífico: de 6 a 8 de outubro de 2008, em Seul (Coreia do Sul); África: de 5 a 7 de novembro de 2008, 
em Nairóbi (Quênia); Europa, América do Norte e Israel: de 3 a 5 de dezembro de 2008, em Budapeste (Hungria); Estados árabes: de 5 a 7 de janeiro de 2009, em Túnis (Tunísia).

Cada um desses encontros contou com a participação de delegações nacionais representando a maioria dos Estados-membros da região, incluindo ministros, vice-ministros e secretários de Estado responsáveis por educação de adultos, além de setores de organizações não-governamentais. Os textos procuraram retratar o contexto regional específico e os desafios a serem enfrentados pela educação de adultos. Também apresentaram uma série de recomendações, incluindo as políticas públicas necessárias para apoiar ações nos níveis regional e internacional. ${ }^{10}$ Esse processo não ocorreu sem forte presença da sociedade civil, em grande parte sob a liderança do ICAE, rede mundial de entidades e movimentos que trabalham com o tema da educação de pessoas adultas. ${ }^{11}$ Nos encontros regionais, as organizações da sociedade civil reuniramse com antecedência, produziram documentos de incidência política e disputaram espaços para influir nos documentos, como já é tradição na maioria dos encontros do sistema das Nações Unidas.

No plano internacional, o ICAE realizou um seminário virtual com seus associados e definiu temas estratégicos de incidência, produzindo análises e reflexões que foram aprofundadas em um seminário presencial na Inglaterra denominado Exploratory Thematic Seminar Preparatory Towards VI CONFINTEA (Leicester, de 23 a 24 de maio de 2008). Todo esse material foi transformado numa publicação específica, em quatro línguas, como subsídio ao processo. ${ }^{12}$ Os quatro temas definidos como prioridade e posterior-

${ }^{10}$ Esses documentos de trabalho, assim como breves relatórios sobre as diferentes conferências, estão disponíveis no site da UNESCO (http://www.unesco.org/en/confintea).

${ }^{11}$ www.icae2.org.

${ }^{12} \mathrm{O}$ material foi publicado inicialmente em número especial da revista Convergence, em 2007, e depois, em espanhol, no site do ICAE. mente tratados em textos para subsidiar os encontros regionais foram:

1. Pobreza e crescente desigualdade social e cultural.

2. Direito à educação e aprendizagem de homens e mulheres imigrantes.

3. Prioridade da educação de pessoas adultas, incluída a alfabetização, como parte dos objetivos da Educação para Todos e como ferramenta crítica para alcançá-las, além de central para alcançar os Objetivos para o Desenvolvimento do Milênio.

4. Necessidade de novas política e legislação para assegurar o direito à aprendizagem sem discriminação por idade, gênero, raça, etnia, classe, orientação sexual, religião ou portadores de necessidades especiais, considerando a dotação de recursos financeiros para tal fim.

Além da mobilização para que o encontro ocorresse no Brasil, o seminário virtual e a publicação, o ICAE realizou várias outras atividades como parte do processo preparatório, entre as quais podemos destacar:

1. organizou a participação do grupo consultivo para a CONFINTEA do IUL como voz da sociedade civil representante de diversas redes mundiais;

2. manteve uma lista virtual com informações atualizadas sobre o processo da CONFINTEA;

3. organizou o primeiro encontro sub-regional africano de capacitação para monitoramento da VI CONFINTEA em Maputo, Moçambique. Essa atividade produziu a aproximação entre as diversas redes de educação na África para trabalhar de forma conjunta com vistas ao encontro regional africano preparatório à CONFINTEA e à conferência mundial no Brasil; 
4. posteriormente, organizou o segundo encontro sub-regional africano em Dacar, Senegal, em março de 2008, também com a finalidade de preparar as organizações da sociedade civil para a participação no encontro regional. Nesse encontro foi criada a Plataforma Africana em Educação de Adultos, com a participação das quatro redes regionais africanas em educação, comunicação e feminista: PAALAE, PAMOJA, ANCEFA e FEMNET;

5. teve papel ativo em providenciar e circular informações em primeira mão para todos os seus membros e parceiros, encorajando-os a participar desse processo, coordenando e fazendo a ponte entre organizações da sociedade civil com as comissões nacionais responsáveis em cada país por meio de relatórios nacionais. Muitos desses relatórios foram produzidos por organizações vinculadas ao ICAE por demanda dos governos, como o caso do NIACE na Inglaterra e DVV na Alemanha. No Uruguai, o ICAE foi apontado como membro da comissão oficial responsável pela preparação do relatório e da participação na CONFINTEA;

6. membros do ICAE que estiveram presentes nas conferências regionais elaboraram documentos que contribuíram para seus resultados. Em alguns casos participaram das comissões de redação dos encontros regionais e trabalharam nos documentos finais.

Outras redes internacionais da sociedade civil também se envolveram no processo preparatório da CONFINTEA. A Campanha Mundial pelo Direito à Educação, articulação de entidades da sociedade civil mundial de educação - mas não exclusivamente de educação de adultos -, estabeleceu como tema para a sua semana de ação global do ano 2009, e como processo preparatório para a CONFINTEA, Ler $e$ escrever o mundo, parafraseando Paulo Freire e dando relevância ao tema do analfabetismo. ${ }^{13}$

\footnotetext{
${ }^{13}$ www.globalcampaignforeducation.org.
}

Finalmente, um conjunto de redes de organizações e movimentos internacionais, nacionais e locais (Belém) tomou a decisão de organizar o Fórum Internacional da Sociedade Civil (FISC), por iniciativa do ICAE, nos três dias que antecedem a reunião oficial, como processo de intercâmbio de ideais e construção de alianças, assim como atividade preparatória para a incidência ao encontro oficial. A primeira reunião ocorreu em 20 de agosto de 2008, com a presença do ICAE, de redes latino-americanas, como o Conselho de Educação de Jovens e Adultos (CEAAL), a Campanha Latino-Americana pelo Direito à Educação (CLADE), a Rede Educação Popular entre as Mulheres (REPEM), entidades e redes nacionais como organizações não-governamentais, como a Ação Educativa e o Instituto Paulo Freire, a Campanha Nacional pelo Direito à Educação, movimentos sociais como o Movimento dos Trabalhadores Rurais Sem Terra (MST), movimentos sindicais como a Confederação Nacional dos Trabalhadores da Agricultura (CONTAG) e a Central Única dos Trabalhadores (CUT). ${ }^{14}$

Essa estratégia de atuação da sociedade civil é costumeira nas reuniões das Nações Unidas: faz-se um encontro anterior ao evento oficial, com a participação de ativistas, pesquisadores e educadores, com o objetivo de intercambiar ideias e propostas, e para conformar novas alianças. Aproveita-se também para preparar a participação no encontro oficial. Uma parte das atividades é de responsabilidade da organização do FISC; outras são compostas por atividades autogestionadas, propostas pelos participantes.

Para preparar a participação da sociedade civil no encontro oficial, organiza-se um caucus cuja estratégia principal é atuar no documento final com vistas a ampliar e garantir os direitos educativos por meio de acordos entre os governos. Procura-se também influir no documento de maneira que se produzam responsabilidades governamentais no campo das políticas afirmativas para os setores menos contemplados por esses direitos em função das condições de classe, gênero, etnia ou outra que os marginalizem perante os demais.

\footnotetext{
${ }^{14}$ Ver www.fisc2009.org.br.
} 
Para tanto, procura-se identificar governos e representantes da sociedade civil que participem do encontro oficial e que tenham identidade com as propostas produzidas no FISC, para que influam na redação dos documentos produzidos. A estratégia desenvolve-se a partir da análise do documento oficial, elaboração de emendas por consenso e finalmente pressão dentro do encontro para viabilizar as emendas. Durante todo o encontro, nas manhãs, há um encontro de avaliação do desenvolvimento dessa estratégia. Também são abordados os membros do comitê de redação e a indicação de representantes da sociedade civil nele.

A participação da sociedade civil também ocorreu no processo de elaboração do documento nacional brasileiro. Os procedimentos para construir o documento nacional foram definidos pela CNAEJA. Uma comissão de consultores foi convidada pela SECAD/ MEC para compor um documento-base orientador que permitisse o debate nos processos estaduais e regionais, elaborado em março de 2008. Depois do processo de consulta, o documento nacional, produzido em setembro de 2008, compunha-se dos seguintes itens:

a) diagnóstico da realidade da educação de jovens e adultos no Brasil;

b) desafios da educação de jovens e adultos no Brasil, compreendendo: sujeitos da EJA; estratégias didático-pedagógicas para a EJA; intersetorialidade da EJA; e EJA no sistema de educação: gestão, recursos e financiamento;

c) recomendações.

As discussões nos encontros estaduais e o exercício de acréscimos, alterações ou supressões no documento-base provocaram diferentes redações e deram origem a novos documentos. Se nos encontros estaduais o critério de participação esteve a cargo da comissão organizadora local, nos encontros regionais e nacional seria necessário compor uma delegação, de acordo com a estratégia desenvolvida pela CNAEJA. Para participar desses encontros foram eleitos, por indicação ou votação, dez delegados e respectivos suplentes, compondo assim as delegações para os regionais e o nacional. Os encontros regionais foram realizados em Manaus (Região Norte), em 29 e 30 de abril de 2008; em Salvador (Região Nordeste), de 23 a 25 de abril de 2008; em Cuiabá (Região CentroOeste), de 23 a 25 de abril de 2008; em Belo Horizonte (Região Sudeste), em 25 e 26 de abril de 2008; e em Florianópolis (Região Sul), em 24 e 25 de abril de 2008. De posse dos documentos finais regionais, os delegados seguiram para a última etapa.

Além dos encontros regionais, o MEC organizou e estimulou a participação da sociedade civil e dos setores públicos em oficinas de diagnósticos que tinham por objetivo capacitar os gestores e interlocutores estaduais para a análise dos dados educacionais referentes à educação de jovens e adultos e para a construção de políticas estratégicas de implantação ou fortalecimento dessa modalidade educacional. Essas oficinas foram organizadas no Centro-Oeste (14 e 15 de fevereiro de 2008), Sudeste (19 e 20 de fevereiro de 2008), Sul (21 e 22 de fevereiro de 2008), Nordeste ( 26 e 27 de fevereiro de 2008) e no Norte (28 e 29 de fevereiro de 2008).

O Encontro Nacional realizou-se em Brasília, entre os dias 28 e 30 de maio de 2008. Nele foi recolhida a produção dos encontros estaduais e regionais e elaborado o documento-base nacional, posteriormente apresentado pelo Brasil na Conferência Latino-Americana, realizada no México em setembro de 2008. Uma delegação ampliada deslocou-se para a cidade do México, com participantes da CNAEJA, convidados e representantes oficiais do governo brasileiro, chefiada pelo secretário da SECAD.

Como pode ser constatado, ocorreu um amplo processo participativo que, para além de construir um documento que pudesse refletir a diversidade de questões produzidas pelos diversos sujeitos e regiões, teve o objetivo de mobilizar atores sociais para o tema da EJA e da CONFINTEA, numa ação preparatória para o encontro em Belém. Em todo esse processo, houve forte presença dos fóruns de EJA, que conduziram as consultas no plano estadual e regional. Além disso, os fóruns priorizaram seus esforços em participar do encontro oficial em Belém, disputando vagas e produzindo pressão para 
que houvesse financiamento para a participação de maior número de representantes dos fóruns.

\section{Educação de jovens e adultos: a dura realidade dos que querem estudar ${ }^{15}$}

Apesar da ampla mobilização da sociedade civil, nos últimos 30 anos, o Brasil manteve como macroproblema educacional, e grande desafio a ser enfrentado, o baixo nível de escolaridade média da sua população, além de ela ser desigual e com qualidade ruim. Em 2007, a escolaridade média era de 7,3 anos, abaixo dos oito anos de escolaridade obrigatória estabelecida como lei desde 1971 (lei n. 5.692/71) e da meta de implantação gradativa dos nove anos até 2010 (lei n. 11.274/06). Essa média cai para 6,3 anos se a população é preta ou parda, 6 anos para os que moram no Nordeste, 5 anos para os $20 \%$ mais pobres e 4,5 anos para a população que vive na zona rural. A desigualdade nos níveis de escolaridade acompanha as conhecidas desigualdades da sociedade brasileira, ajudando a reproduzi-las. ${ }^{16}$

Vários são os motivos que levam a essa situação, todos já bastante conhecidos: além dos fatores sociais que condicionam a aquisição da escolaridade, o acesso é restrito na educação infantil e há níveis insuficientes de permanência e desempenho no ensino fundamental, unidos ao tema das desigualdades e da baixa qualidade do ensino ofertado. Com isso, produzimos uma escolaridade insuficiente para quem permanece na escola e excluímos dela um contingente significativo de pessoas sem completar sua escolaridade.

Em 2007 a população brasileira com 15 anos ou mais era de 141,5 milhões de pessoas. Dessas, 14,1 milhões não sabiam ler nem escrever, ou seja, 10\% dos jovens e adultos. Apenas 2,9\% dos jovens analfabetos

${ }^{15}$ Esta seção foi editada a partir de artigo com o mesmo nome publicado no jornal Brasil de Fato, reproduzida no site do mesmo nome em 19 de junho de 2009. Ver: http://www.brasildefato.com. br/v01/agencia/analise/educacao-de-jovens-e-adultos-a-durarealidade-dos-que-querem-estudar.

${ }^{16}$ Conforme dados do documento CDES (2009). entre 15 e 24 anos frequentavam algum curso de alfabetização. Entre os adultos (acima de 24 anos), apenas $1,8 \%$. De cada 100 pessoas que saem dos programas de alfabetização, apenas seis têm continuidade em programas de educação de jovens e adultos. Isso é grave porque os cursos que correspondem à primeira metade do ensino fundamental são responsáveis por sedimentar o aprendizado realizado em programas de alfabetização. Afinal, os seis a oito meses dos cursos de alfabetização são apenas um primeiro passo nesse processo, que deveria ter continuidade até o término do ensino médio.

Dessa maneira vão sendo produzidos os "analfabetos funcionais": aqueles que passaram pela escola e não têm o domínio suficiente da leitura e da escrita para utilizar no seu cotidiano, no seu trabalho, na sua vida em geral. Podemos medir esse indicador, por exemplo, com aqueles com 15 anos ou mais que só tiveram até três anos de estudos. E são muitos: 15,5 milhões de pessoas. Se somarmos aos 14 milhões que não sabem ler nem escrever, chegamos a quase 30 milhões da população brasileira, 22\% dos jovens e adultos que são incapazes de utilizar a leitura e a escrita.

O relatório do Instituto Brasileiro de Geografia e Estatística (IBGE) Aspectos complementares da educação de jovens e adultos, elaborado com base nos dados da Pesquisa Nacional por Amostra de Domicílios (PNAD) de 2007, mergulha nesse universo e traz dados que ajudam a compreender o fenômeno e a apontar soluções. Em primeiro lugar, mostra o baixíssimo número de pessoas estudando em salas de EJA. Apenas 2\% do total da população com 15 anos ou mais em 2007, ou seja, 2,9 milhões de pessoas. A maioria é de mulheres (54\%), com baixa renda, na faixa etária entre os 18 e 39 anos de idade, demonstrando claramente que a EJA não tem sido uma válvula de escape para os adolescentes da escola regular, mito bastante difundido.

Outra informação importante é que os alunos estão frequentando ou frequentaram principalmente o segundo segmento do ensino fundamental ou o ensino médio. Uma minoria cursou a primeira metade do ensino fundamental. Isso demonstra que as pessoas 
que querem complementar seus estudos têm mais facilidade de acessar a EJA do que aqueles que buscam consolidar sua capacidade de ler, escrever e contar.

Sobre a motivação de frequentar os estudos, $70 \%$ responderam que era para voltar a estudar ou para adiantar os estudos (fazê-lo de forma mais rápida). Apenas 19\% dos entrevistados responderam que a motivação para estudar era conseguir melhores oportunidades de trabalho. Essas respostas apontam para um interesse maior dos alunos em sua formação geral do que um olhar instrumental para a escola como acesso para melhores empregos, demonstrando a importância desses cursos para a construção de cidadania.

Dentre os motivos para a não-conclusão do curso de EJA, os principais foram: horário das aulas não compatível com o horário de trabalho ou de procurar trabalho $(27,9 \%)$, ou com o horário dos afazeres domésticos $(13,6 \%)$; não haver curso próximo à residência $(5,5 \%)$; não haver curso próximo ao local de trabalho $(1,1 \%)$; não ter interesse em fazer o curso (15,6\%); dificuldade de acompanhar o curso (13,6\%). Apenas $0,7 \%$ disseram não ter conseguido vaga. Os dados demonstram que uma das dificuldades principais para o aluno frequentar a EJA é a inadequação ou inexistência dos cursos ou horários compatíveis com a vida dessa população jovem e adulta. É por isso que, dos poucos que foram atendidos até 2007, 42,7\% largaram os estudos.

As informações sobre inexistência, insuficiência ou inadequação na oferta de cursos, unidas ao fato de que apenas parcela mínima dos que frequentam cursos de alfabetização tem continuidade nos programas de EJA e o fato de que apenas $24 \%$ das escolas públicas oferecem EJA, apontam para os principais problemas no atendimento dessa parcela da população.

O Plano Nacional de Educação, aprovado em 2000, estabeleceu a meta de erradicar o analfabetismo até 2010, além de assegurar para 2005 a oferta de educação de jovens e adultos equivalente às quatro séries iniciais do ensino fundamental para 50\% da população de 15 anos e mais, e até 2010 a oferta de cursos equivalentes às quatro séries finais do ensino fundamental para toda a população de 15 anos e mais que concluiu as quatro séries iniciais. Estamos, por- tanto, bastante longe dessas metas, apesar da pressão e do papel da sociedade civil.

\section{Os desafios da sociedade civil e o movimento por educação de jovens e adultos: algumas conclusões}

O movimento de educação de adultos no Brasil vem crescendo nos últimos anos, com diversas características organizativas, mantendo relações de colaboração e conflito com as diversas instâncias de governo.

Depois da forte presença na luta pela conquista do direito à escolarização de jovens e adultos na Constituição Federal de 1988, o movimento reorganizou-se para opor resistência às políticas neoliberais da segunda metade da década de 1990. Naquela ocasião, o movimento se opôs às restrições financeiras impostas pelo FUNDEF e à diminuição do escopo de valorização da EJA na LDB de 1996, além da franca oposição ao PAS. Como vimos, esse descontentamento apresentou-se de maneira aguda no processo de preparação da V CONFINTEA, em 1997, no qual “os seminários preparatórios acirraram as divergências entre os representantes dos diferentes segmentos sociais e as autoridades federais que, adotando um estilo vertical e delegativo de coordenação política, optaram por fechar os canais de diálogo até então existentes" (Di Pierro, 2005, p. 1.130).

A partir daí, e como consequência do próprio processo preparatório, o movimento adotou a estratégia de constituição dos fóruns de educação de jovens e adultos, espaços abertos, com baixo grau de institucionalidade, não-partidário, reunindo organizações não-governamentais, movimentos sociais, entidades privadas e organismos governamentais.

Os fóruns vêm pautando um conjunto de questões ao longo destes últimos anos. Conforme Di Pierro (2005) e Soares (2004), a primeira das questões colocadas pelos fóruns aos dirigentes educacionais refere-se à articulação entre os programas de alfabetização e os níveis mais elevados de escolarização, de modo que se garanta aos jovens e adultos a continuidade de estudos. 
Por um lado, trata-se da exigência de garantia efetiva do direito ao ensino fundamental público e gratuito, constitucionalmente reconhecido mas ainda não assegurado. Por outro lado, reflete a adesão ao paradigma da educação continuada ao longo da vida e à concepção ampliada de alfabetização que, diante do aumento das exigências sociais de leitura, escrita e conhecimentos matemáticos, reivindica processos de aprendizagem mais ricos e alongados que, para além dos conhecimentos sobre o funcionamento do sistema de escrita e das técnicas de cálculo, assegurem o letramento, entendido como o desenvolvimento de habilidades, conhecimentos e atitudes que favoreçam o uso desses conhecimentos nas mais diversas práticas sociais.

Outras questões postas dizem respeito ao financiamento das ações de EJA, à permanente tensão entre o propósito de inserção orgânica da educação de jovens e adultos nos sistemas de ensino e a necessária flexibilidade para responder às necessidades de formação de sujeitos sociais muito diversos; à formação inicial e continuada de educadores, à precariedade do mercado de trabalho, que não proporciona a construção de carreiras profissionais, e ao escasso envolvimento das instituições de ensino superior na temática. Essas questões têm sido levadas aos encontros estaduais e aos ENEJAs, com pouco poder de pressão e eficácia para provocar mudanças significativas que possam resultar na ampliação e melhoria das políticas de EJA.

O desenvolvimento desse histórico coloca o desafio de pensar o papel que a sociedade civil pode ter na defesa do direito humano à escolarização de pessoas jovens e adultas e na implementação de políticas que efetivem esse direito. Por sua vez, a iminência da VI CONFINTEA a ser realizada no Brasil coloca desafios novos para o movimento de educação de jovens e adultos. Diferentemente do que ocorreu na última conferência, o momento atual se conforma como de diálogo e parceria do movimento de educação de adultos com o governo federal. Isso tem ocorrido em diversos campos das políticas públicas nos quais a participação da sociedade civil vem se envolvendo.

A Constituição Federal de 1988, além de garantir direitos, definiu importantes mecanismos de participação, como o plebiscito, o referendo popular, a iniciativa popular de lei, a tribuna popular e a audiência pública. Além do mais, estabeleceu mecanismos de participação legalmente constituídos, como os conselhos de gestão e as conferências setoriais. Com o Governo Lula, tais espaços cresceram, especialmente em nível nacional. Dos 64 conselhos federais, 11 foram criados e nove restabelecidos. No primeiro mandato do Governo Lula, 38 conferências nacionais foram organizadas, além das conferências estaduais e municipais preparatórias, com mais de 2 milhões de participantes. ${ }^{17}$ Todas essas iniciativas procuraram levar ao aprofundamento da democracia brasileira, garantindo direitos sociais de cidadania.

Após alguns anos de experiência participativa, muito se tem discutido sobre o efetivo impacto da participação da sociedade civil nas políticas públicas. No artigo “Até onde vai a participação cidadã”, Ana Claudia Teixeira ${ }^{18}$ procura responder às seguintes questões:

\begin{abstract}
Mas a que têm servido todos esses espaços? Qual é o significado de todas essas mobilizações? Qual o papel que exerce na democracia brasileira? É possível dizer que outros atores sociais vieram à cena por meio desses espaços? Acaso provocaram eles mais igualdade, mais acesso e melhor qualidade dos serviços públicos? Como aperfeiçoar os mecanismos de participação? Como tornar a democracia participativa mais democrática e mais participativa? E como fazer dela instrumento de maior justiça social?
\end{abstract}

A autora convida para um balanço desses vinte anos pós-Constituição Cidadã e, após análise de experiências no plano local e nacional, conclui:

a democracia brasileira, ao mesmo tempo que inaugura uma ampla variedade de interfaces governo/sociedade, não as inclui como elementos de uma renovada arquitetura institucional, capaz de oferecer caminhos novos e alternativos à reforma democrática do Estado e à governabilidade.

A impressão é de que as experiências participativas no Bra-

\footnotetext{
${ }^{17}$ Sobre a temática veja www.participacaopopular.org.br

${ }^{18}$ Le Monde Diplomatique Brasil, fev. 2008.
} 
sil, mundialmente reconhecidas, "correm por fora", ficando na periferia do sistema, afetando pontualmente uma ou outra política setorial, a depender da vontade política dos governos e/ou do poder de pressão da sociedade organizada. Elas parecem não resultar de - ou induzir - uma estratégia mais profunda de articulação entre representação e participação. Em alguns casos, é possível dizer até que, mesmo quando o governo aloca recursos que resultam em efeitos redistributivos, tal procedimento não se distingue das estratégias conservadoras de manutenção do poder e de velhas práticas clientelistas. (Teixeira, 2008, p. 5)

Não caberia ao movimento de EJA um balanço como este diante dos tímidos resultados destes últimos anos no campo dos direitos educativos das pessoas jovens e adultas? Estariam os setores da sociedade civil atuando de maneira efetiva para implementação desses direitos? Sem descartar os avanços, estamos efetivamente satisfeitos com os resultados conquistados até hoje? Não seria a VI CONFINTEA um bom momento para exercitar esta reflexão?

São perguntas que merecem outro artigo para tentar respondê-las - sem dúvida alguma um grande desafio necessário para avançar o movimento de EJA.

\section{Referências bibliográficas}

AGOSTINHO, Ana; HINZEN, Heribert; KNOLL, Joachim (Orgs.). Convergence. Leicester: ICAE/NAIACE, v. XL (3-4), 2007.

CDES - CONSELHO DE DESENVOLVIMENTO ECONÔMICO E SOCIAL. Oficina de indicadores de equidade do sistema tributário nacional e desigualdades na escolarização no Brasil - Caderno Especial. Brasília: CDES/Presidência da República, 2009.

DI PIERRO, Maria Clara. Notas sobre a redefinição da identidade e das políticas públicas de educação de jovens e adultos no Brasil. Educação \& Sociedade, v. 26, n. 92, p. 1.115-1.139, 2005. .; VÓVIO, Claudia; ANDRADE, Eliane Ribeiro. Alfabetização de jovens e adultos: lições da prática. Brasília: UNESCO, 2008. FARIA FILHO, Luciano Mendes. Educação para todos: quais os desafios para as ONGs? ONGs e Educação, Belo Horizonte: UNICEF/FDDCA/MG, 1994.

HADDAD, Sérgio. Ensino supletivo no Brasil: estado da arte. Brasília: INEP, 1987.
. Una mirada sobre la CONFINTEA a partir del pensamiento de Paulo Freire. La Piragua, México, n. 14, p. 18-25, 1998. (Org.). Educação de jovens e adultos no Brasil (1986-1998). Brasília: Ministério da Educação/Instituto Nacional de Estudos e Pesquisas Anísio Teixeira, 2002.

.; OLIVEIRA, Anna Cinthia. As organizações da sociedade civil e as ONGs de educação. Cadernos de Pesquisa, n. 112 , p. $61-83$, mar. 2001.

IBGE. Aspectos complementares da educação de jovens e adultos, baseado nos dados da Pesquisa Nacional por Amostra de Domicílios. Brasília, 2007.

PAIVA, Jane. Educação de jovens e adultos: movimentos pela consolidação de direitos. Reveja - Revista de Educação de Jovens e Adultos, v. 1, n. 0, 2007.

SAVIANI, Dermeval. Escola e democracia. 40. ed. Campinas: Autores Associados, 2008.

SOARES, Leôncio José. O surgimento dos fóruns de EJA no Brasil: articular, socializar e intervir. Alfabetização \& Cidadania, n. 17, p. 25-35, maio 2004.

TEIXEIRA, Ana Claudia. Até onde vai a participação cidadã? Le Monde Diplomatique Brasil, ano 2, n. 7, p. 6-7, fev. 2008.

UNESCO. Boletim, n. 1, fev. 2009.

SÉRGIO HADDAD, doutor em história e sociologia da educação pela Universidade de São Paulo (USP), é pesquisador e coordenador geral da Ação Educativa, em São Paulo. Algumas publicações mais recentes: Novos caminhos em educação de jovens e adultos (Coord.) (São Paulo: Global/FAPESP/Ação Educativa, 2007), "Education of youth, human rights and human development" (Convergence,Toronto, v. XXXIX, p. 131-146, 2006); com Maria Clara Di Pierro: "A historical overview of adult formal education in Brazil” (In: CASTRO, Rui Vieira de; SANCHO, Amélia Vitória; GUIMARÃES, Paula (Orgs.). Adult education: new routes in a new landscape. Braga: University of Minho, 2006. v. 1. p. 231-270); com Mariângela Graciano (Orgs.): A educação entre os direitos humanos (Campinas: Autores Associados, 2006). É pesquisador do Conselho Nacional de Desenvolvimento Científico e Tecnológico $(\mathrm{CNPq})$, atualmente desenvolvendo a pesquisa: "Educação nãoescolar de adultos: um balanço de práticas educativas". E-mail sergiohaddad@terra.com.br

Recebido em março de 2009 Aprovado em abril de 2009 
has now become the major paradigm within educational theory and practice. This is even more so in the context of organizations like UNESCO, the European Union and the German Adult Education Association (DVV). There are clear indications that these levels - global, regional and national - and their respective organizations influence each other via policies, programmes, models and even funding procedures. This is exemplified here by looking at processes that have been gaining importance in the last few years as part of the preparation for the coming VI International Conference on Adult Education - VI CONFINTEA.

Key words: adult education in Europe; VI CONFINTEA.

Educación de adultos

a lo largo de la vida: desarrollos actuales e en Alemania, en Europa y fuera de ella, en el camino de la VI CONFINTEA

La educación y aprendizaje de adultos ha recibido más atención y reconocimiento a partir del concepto de aprendizaje a lo largo de la vida, que se vuelve ahora el principal paradigma para la teoría y práctica de educaciones. Este movimiento se destaca en el contexto de organismos como UNESCO, la Unión Europea y la Asociación Alemana de Educación de Adultos - DVV, en el caso de Alemania. Hay indicaciones claras de que cada uno de esos organismos ejerce mutua influencia en los otros, por medio de las políticas, programas, modelos y hasta mismo por la administración de recursos financieros. Esto es ejemplificado en el artículo por la indicación de procesos que vienen teniendo importancia en los últimos años, en la preparación de la próxima conferencia mundial de educación de adultos, la VI CONFINTEA.

Palabras claves: educación de adultos en Europa; CONFINTEA VI.
Sérgio Haddad

A participação da sociedade civil brasileira na educação de jovens e adultos e a CONFINTEA VI

Este artigo tem por objetivo discutir a participação da sociedade civil no contexto da VI CONFINTEA e as questões trazidas no seu processo preparatório.

Para tanto, história como veio se dando esta participação ao longo da história recente do Brasil, em diálogo com a constituição das políticas públicas em educação de jovens e adultos (EJA), discutindo a relação entre o poder público e a sociedade civil. Retoma o processo preparatório relativo à $\mathrm{V}$ CONFINTEA, ocorrida em 1997, em Hamburgo, na Alemanha, e a consequente formação dos fóruns estaduais de educação de jovens e adultos e dos encontros nacionais desses fóruns, os Enejas, conformando um modo particular de participação.

Palavras-chave: VI CONFINTEA; participação da sociedade civil.

Civil society participation in adult and youth education and the VI

\section{CONFINTEA}

The objective of this article is to discuss civil society participation in the context of the VI CONFINTEA and questions to which the preparatory process has given rise. To that end, it recounts the way in which this participation has occurred in recent Brazilian history in dialogue with the constitution of public policies of adult and youth education, whilst discussing the relation between public power and civil society. It goes back to the preparatory process for CONFINTEA V, which took place in Hamburg (Germany) in 1997 and the resulting creation of the state forums of adult and youth education and the national meetings of these forums - ENEJAS, giving expression to a particular type of participation.

Key words: VI CONFINTEA; civil society participation.
La participación de la sociedad civil en la educación de jóvenes y adultos y la VI CONFINTEA

Este artículo tiene por objetivo discutir la participación de la sociedad civil en el contexto de la CONFINTEA VI y las cuestiones traídas en su proceso preparatorio. Por tanto, relata la historia de como vino dándose esta participación a lo largo de la historia reciente de Brasil, en diálogo con la constitución de las políticas públicas en educación de jóvenes y adultos (EJA), discutiendo la relación entre el poder público y la sociedad civil. Retoma el proceso preparatorio relativo a la CONFINTEA V, ocurrido en 1997, en Hamburgo, en Alemania, y la consecuente formación de los foros estaduales de educación de jóvenes y adultos y de los encuentros nacionales de estos foros, los ENEJAs, conformando un modo particular de participación. Palabras claves: VI CONFINTEA; Brasil; participación; sociedad civil.

Nilton Bueno Fischer

Educação não-escolar de adultos e educação ambiental: um balanço da produção de conhecimentos

O objetivo do artigo é analisar a produção de conhecimento presente na relação entre os campos da educação de adultos e educação ambiental em projetos e práticas não-escolares, explicitada em 39 dissertações e teses produzidas em universidades brasileiras entre 1988 e 2006. A análise das dissertações e teses reafirma a necessidade da escuta dos sinais da natureza pela voz das pessoas das classes populares em suas interações em diferentes práticas sociais, dados os novos desafios postos pelo desdobramento das "intervenções” do homem no equilíbrio das relações homem-natureza. No balanço da produção ficou evidenciada, de forma predominante, uma intencionalidade dos pesquisadores em 